This is a preprint of a chapter accepted for publication by Facet Publishing. This extract has been taken from the author's original manuscript and has not been edited. The definitive version of this piece may be found in Bold minds: Library leadership in a time of disruption (pp. 179-210), Facet, London, ISBN 978-1-78330-453-0, which can be purchased from www.facetpublishing.co.uk

\title{
Databrarian Ed? Preparing Information Specialists for Participation in an Open Datafied Society
}

\author{
Sheila Corrall
}

\section{Introducing the imperatives for change}

Environmental scans, futures studies and technology assessments have defined multiple trends affecting the library profession in the 21st century, but arguably it is the confluence of three currents that has transformed the information landscape and will continue to shape our professional future - the open movement, participatory culture and the data revolution. Industry commentators, thought leaders and enterprising practitioners have evolved new service models for the changing digital world surrounding us. Professional educators are similarly reviewing curricula, rethinking pedagogies and redesigning programmes to meet the needs of the present and future workforce. This chapter explores the challenges and debates surrounding pre-service education and continuing professional development for an environment in which data literacy, user experience, open scholarship, community engagement, relationship management and social impact are among the keys to success for all information service organisations. We start with the three forces driving behaviour around information and then consider library responses to these movements, we next review developments in professional education and its response to the challenges, and finally look at how we can transform professional learning to create a better future.

Open initiatives have moved beyond open access to research, open source software and open courseware to encompass other open products (open textbooks, MOOCs, open data), domains (open government, open science, open cultural heritage) and practices (open innovation, open peer review, open pedagogy). The open movement has its origins in the preprint servers, free online journals and networked digital libraries of the 1990s but took off properly in the early 2000s with MIT OpenCourseWare launching the open educational resources (OER) movement and the Budapest Open Access Initiative doing the same for open access (OA). In addition to MOOCs in their many forms, other notable developments of this decade include the evolution of open licensing through the Creative Commons movement, open badges, and proliferation of terminology and taxonomies to define different kinds of openness within the various open domains. Thus the original distinctions between green and gold OA have now been supplemented by diamond/platinum, bronze/fourrée, hybrid, predatory and black (pirated) OA. 
A key point here is that only 20 years after Stevan Harnad's 'subversive proposal' of 1994, industry experts reckoned OA had passed the 'tipping point' with a majority of American and European papers from the previous five years accessible online (Archambault et al, 2014).

Like the open movement, the origins of participatory culture go back to at least the 1990s, but its practical expression gained huge momentum from developments in networking technologies, Internet access and online services over the following decade, particularly Web 2.0 and social networking services. The concept is credited to American media/cultural scholar Henry Jenkins, who introduced the term in his 1992 book Textual Poachers and then elaborated the concept in a white paper on digital media and learning:

'a culture with relatively low barriers to artistic expression and civic engagement, strong support for creating and sharing one's creations, and some type of informal mentorship whereby what is known by the most experienced is passed along to novices' and 'in which members believe their contributions matter, and feel some degree of social connection with one another' (Jenkins et al, 2006, 3).

Participatory culture emphasises access, collaboration and empowerment and is characterised by changes in interactions and relations between consumers and producers (user-generated content), giving rise to the concepts of 'prosumption' and 'produsage' (Bruns, 2013) and an emphasis on collective rather than individual agency. Related developments include blogging; commons-based peer production models, notably Wikipedia; video hosting, streaming and sharing sites (Vimeo, YouTube); multimedia publishing and transmedia storytelling; and crowdsourcing (Howe, 2006). Participatory/2.0/citizen approaches have been promoted in various domains such as medicine, journalism and science (and in libraries), though definitions and levels of participation (and empowerment) vary across and within different domains.

Data is the big story of the past decade, generating a vast quantity of academic, business, technical and popular literature showing us how data has pervaded every sector of the economy and society and is impacting our professional, civic, personal and social lives. While data have long been used for decision support and business intelligence, the data revolution has its origins in the fourth scientific paradigm of data-intensive discovery, based on data mining and machine learning with vast amounts of data. Big data, particularly the growth of freely-accessible non-proprietary open data on the web, along with the tools to analyse, visualise, mine and manipulate such enormous datasets, is also central to the 'fourth industrial revolution', which represents a step-change from the previous digital revolution in its speed, scale and scope, with a fusion of emergent technologies such as artificial intelligence, robotics, 3D printing and the Internet of Things that is blurring the boundaries between the physical, digital and biological worlds.

Hailed as 'the new oil' and the new medium of exchange for science, business and government, beyond the hype big data has become the key competitive asset for productivity and innovation in the private, public and nonprofit sectors. Data analytics and data scientists play an important part in many organisations, where data-driven decision making is central to evidence-based 
policy and practice; notably in schools, where data literacy for teachers is all about data-based decision making in education. The data decade has also generated other new vocabulary to capture its significance and salient features, including data capitalism, data double, data exhaust, datafication, datalisation, datapalooza, data refineries, dataveillance, the 'quantified self' and the 'analytics of things', as well as databrarianship. The three key drivers of openness, participation and datafication have moved from potential influences and special interests to universal imperatives for libraries and librarians, whose responses to the challenges can provide vital signals to professional educators about the general health of their current curricula and specific directions for future programmes.

\section{Trends in the information environment}

Overall we find many examples of the profession evolving and adapting strategies and practices to reflect the move towards openness, participation and data in the environment, with several areas (such as scholarly publishing, hands-on co-creation, learning facilitation and new literacies) where libraries are actively participating and creatively leading the design and development of new models for open collaborative resources and services. But there are areas where more could and should be done to embed and institutionalise new approaches and where more working across traditional boundaries would benefit community members, which in turn offer opportunities for professional educators to stimulate new thinking rather than perpetuating outdated practices.

\section{The open agenda}

The open movement speaks to library values of access, the public good and social responsibility and to practical needs for affordable content and cost-effective infrastructure. Libraries are engaging with the open agenda individually and through professional associations and community organisations in collaboration with other stakeholders. Librarians have been OA activists from the outset, progressing from a focus on OA education and advocacy via repository management and policy compliance to direct involvement in scholarly publishing and policy development, including workflow coordination and systems integration across the research lifecycle (Awre, Stainthorpe, and Stone, 2016; Cryer, 2011; Otto and Mullen, 2019). Research libraries like the University of Pittsburgh use open source tools for their publishing activities and are formal partners in the software development process as they help journals to 'flip' from subscription-based models to OA (Collister and Deliyannides, 2014).

Libraries are also involved in adoption, adaptation and creation of OERs, including open textbooks, particularly in the USA with grant programs to incentivise educator take-up and compliance with institutional and state policies covering higher education and/or the K-12 sector (Reed and Jahre, 2019). Academic librarians are supporting teachers and students in their use of MOOCs (Barnes, 2013), while public librarians have hosted MOOC meet-ups to facilitate blended learning in a collaborative environment (Pawlowski, 2017). Librarians are using MOOCs for professional development (Bond, 2013) and also developing MOOCs/OERs for adult learners and students (Denlinger, 2016; Murphy and Tilley, 2019). 
Additional open activities in libraries encompass open science (Schmidt et al, 2018), open infrastructure (Lewis et al, 2018) and linked open data (ARL, 2019; Ullah et al, 2018). Public librarians around the world are engaging with open government agenda and connecting their communities with open data, helping people to find, use, apply and publish local data, in their traditional roles as 'civic infomediaries' (Ayre and Craner, 2017; Robinson and Mather, 2017). In the Pittsburgh Civic Switchboard project (https://civic-switchboard.github.io) public and academic librarians are partnering with the regional open data portal and the National Neighborhood Indicators Partnership to develop library worker capacity to act as core data intermediaries in civic open data ecosystems. Public, academic and national libraries are also using open innovation processes to improve their spaces and services (Henkel et al, 2018).

Librarians have demonstrated commitment to openness and have the capacity to make operational, tactical, and strategic interventions to deliver real benefits to their communities and society, as users and producers of open content, processes and infrastructure, and by fulfilling roles as educators, advocates, facilitators, mediators, collaborators, coordinators, integrators and leaders of the open movement (Corrall, 2015). But they can do more to build the institutional culture to make open our default way of working and living (Hamilton, Kernohan and Jacobs, 2017). Libraries are uniquely positioned to make connections between open domains and promote more joined-up thinking and practice to create an accelerator effect instead of the present 'silo effect' that is slowing progress by pursuing openness along parallel tracks and isolating rather than integrating open initiatives and mainstream activities.

Our core missions of collection development and information literacy must be key targets. Librarians have been urged to 'integrate and mainstream the curation, organization, and use of open access research and educational resources into the workflows and services of their libraries', including collection policies and discovery systems, by explicitly integrating 'open' into their strategic planning (Petrides, Goger and Jimes, 2016, 6-7). Many libraries already select free e-books and other open web resources for their users, but they are often not formally catalogued nor easily discovered (Hill and Bossaller, 2013; Yang and Henry, 2015). The next step to move openness from an espoused value to a meaningful commitment is to 'flip' the collection, like the University of Massachusetts Amherst, which is 'pivoting from materials produced by proprietary publishers to a mix of investments in unique and special collections; open access publishing, content and infrastructure; and materials published through traditional channels' (Turner and Billings, 2019, 195). We must similarly mainstream open content (alongside proprietary resources) in information literacy education to help everyone routinely leverage OA resources/OERs by adopting frameworks designed for the open online world, such as the metaliteracy model of Jacobson and Mackey (2013).

\section{Participatory (2.0) librarianship}

The concept of participatory librarianship or 'libraries as participatory conversations' was promoted by David Lankes in a technology brief on social networking for the American Library Association (Lankes, Silverstein and Nicholson, 2007, 24) and elaborated in his 2011 Atlas of New Librarianship. Around the same time public library technology director Michael Casey 
developed his concept of Library 2.0, emphasising 'user-centered change' through 'a model for library service...inviting user participation in the creation of both the physical and the virtual services they want' (Casey and Savastinuk, 2006, 40), equated with 'participatory library service' (Casey and Savastinuk, 2007). The notion of Library 2.0 proved hugely popular, though its proponents stressed it was not dependent on 'cool technologies', but about adopting a service mindset or philosophy based on Web 2.0 concepts (notably collective intelligence/crowdsourcing and customisation/personalisation), and principles such as Conversations, Community, Participation, Experience and Sharing representing 'the application of open, participatory thinking to library services' (Stephens, 2007, 255).

Library 2.0 generated white papers, public and academic library case studies and applications of 2.0 to a range of library practices (cataloguing 2.0, OPAC 2.0, collection 2.0, information literacy 2.0, reference services 2.0 and technology help 2.0). However Library 3.0 (Kwanya, Stilwell and Underwood, 2015) did not get the same traction, representing a more evolutionary transition to more sophisticated tools emphasising systems integration, intelligent systems (smart searching) and apomediation (a participative, collaborative, transparent form of technologyassisted mediation) for a step-change in personalisation. The Lankes model of participation is not simply less technology-centric, it has a different theoretical foundation in Pask's conversation theory of learning and how it occurs (in both humans and machines) and signals the need for libraries and librarians to participate in the activities of their users and communities as well as vice versa, anticipating later debate around putting the library and librarian in the workflows and lifeflows of their users (Brophy, 2008; Connaway, 2017).

Lankes's $(2011,330)$ argument is that libraries are in the knowledge business, knowledge is created through conversation, so librarians are in the business of facilitating conversation via access, knowledge, environment and motivation, summarised as 'get them to a conversation knowing what they are doing and help them feel safe and compelled to participate'. The mission of librarians is 'to improve society through facilitating knowledge creation in their communities', which requires 'instructional skills in all librarians regardless of title or function' (reference, technical and administrative staff 'are all part of the instructional process') and expansion of information literacy to include 'conversational literacy' and other literacies (Lankes, 2011, 15, 72-3) - a development evident in contemporary reframing of information literacy for the Web 2.0 environment (ACRL, 2015; Jacobson \& Mackey, 2013). The 'participatory library' label was less popular than 'Library 2.0' and used more in Europe, Asia and Australia than in America (Hopkins et al, 2015; Hvenegaard Rasmussen, 2016; Nguyen, 2015).

Despite differences in emphasis, the 2.0 and participatory models use similar language. Kwanya et al $(2015,4)$ note the $2.0 / 3.0$ shift from information as commodity to 'information as conversation', reflected in the ACRL (2015) Framework for Information Literacy ('scholarship as conversation'); Hvenegaard Rasmussen (2016) describes the participatory library shifting from collections to connections, from access to participation, from one-way communication to dialogue and from clients to partners; while Nguyen's (2015) model has three central components (Community, Empowerment and Experience) and the eight subcategories include 
connection, sharing and partnering. The legacy of the participatory library is manifest in a renewed interest in internal, local and global collaboration, including 'all-in' deep and radical models (Atkinson, 2018; Horton, 2013; Neal, 2011), a strategic focus on engagement and embedded librarianship (Díaz, 2014; Schlak, 2018; Shumaker, 2012) and growing deployment of participatory design methods, library anthropologists/ethnographers and user experience (UX) librarians (Fried Foster, 2014; Priestner and Borg, 2016).

New OA community-published journals, such as Code4Lib (2007, a 'contribution to the developing culture of collaboration around library technology'), Collaborative Librarianship (2009) and Weave (2014, a 'journal for Library User Experience professionals') are other tangible examples of the participatory culture of librarianship, along with the makerspaces and similar facilities such as hackerspaces, fablabs (fabrication laboratories), media labs, learning labs, idea labs, tech shops, innovation centres, invention studios and design studios that are now commonplace in public, academic and school libraries worldwide in addition to maker clubs, mobile/pop-up spaces and maker kits circulated like books (Mann, 2018; Nichols, Melo and Dewland, 2017; Wang et al., 2016).

\section{Dealing with data}

The data revolution has penetrated all areas of frontline and backroom work in libraries and turned research libraries in particular into data-intensive organisations as a result of developments in linked data and disciplinary metadata, patron- or demand-driven acquisitions, digital scholarship and open science, bibliometrics/altmetrics, text and data mining, data-based decision making and learning analytics. Bibliographic data has always been the substance of cataloguing, but other quantitative and qualitative data and data visualisations from diverse sources are now central to collection development, research services, reference transactions, information literacy, library assessment and UX evaluation (Kellam and Thompson, 2016; Weiss, 2018). Data-intensive work carried out by data specialists and in other library specialties spans government information, liaison/subject librarianship, research support, reference and instruction to help students and faculty handle and interpret civic and research data, spatial and numeric, open and restricted data.

Public libraries are similarly engaging with data, notably via community data, social media data and data literacy (Ayre and Craner, 2017; Bowler, Acker and Chi, 2019; Robinson and Mather, 2017). Zhan and Widén (2018) define eight big data roles for public libraries split into serviceoriented (adviser, educator, advocator, marketer, organisation-server and service-developer) and system-oriented (data organiser and data container), but found limited involvement in Finland, though study participants recognised the roles. US teen services librarians envision four participatory roles for library data intermediaries: data conversationalists, data teachers, data agents and data hubs (Bowler et al, 2019a). Academic, public and school libraries are reframing their conceptions of data literacy for the participatory (prosumption/produsage) environment and librarians in education settings are promoting life-wide learning by integrating academic, professional and personal versions of data literacy (Fontichiaro and Oehrli, 2016; Macy and Coates, 2016; Shanley and De Voe, 2018). Examples of expanded understandings include 'data 
information literacy' (Carlson et al, 2011), 'data informed learning' (Maybee and Zilinski, 2015), 'critical data literacy' (Shanley and De Voe, 2018) and 'data infrastructure literacy' (Bowler et al, 2019a).

Libraries are using various methods to develop staff for data-related work, including formal education, external or in-house training courses (including scenario-based workshops) and supervisor-/peer-assisted or self-directed informal learning (including secondments to specialist teams and projects, as well as individual exploration of new tools and trends via literature and online training resources). Brown, Wolski and Richardson $(2015,229)$ present the research data management (RDM) roles of academic librarians as 'a continuum of increasing complexity' from advisory services to hands-on involvement, and suggest mixing formal skills training with informal learning facilitated by coaching/mentoring and support networks of specialists. The University of Michigan implemented a three-stage library-wide education programme that reached a quarter of their staff, progressing from general data literacy to 'deep dives' into disciplinary data cultures and advanced data concepts (Martin and Oehrli, 2016). Their 'Deep Dive into Data Workflow' (http://hdl.handle.net/2027.42/117636) is a useful tool for subject liaisons to explore the data landscape around a particular discipline.

The University of Pittsburgh also used 'disciplinary deep dives' and active learning to develop understanding of disciplinary data practices among 'specialist' and 'advanced' RDM service providers and to build awareness of RDM practices across domains among 'basic' service providers (Mattern, Brenner and Lyon, 2016). Their three levels of service provider reflect their tiered service-delivery model adapted from the inclusive three-layer "'triangle" service model' for research support developed at the University of Queensland (Brown et al, 2018, 341-2). The first (base) layer includes staff who are aware of research support services, but do not routinely provide same; the second layer includes staff who provide discipline-driven support, but may refer 'complex, unusual or extensive' enquiries to staff in the third layer, who provide expertlevel services, work with discipline liaisons on upskilling within their specialties and collaborate on service delivery. Their deep-dive active-learning approach was modelled on an assignment from the Pittsburgh iSchool RDM course (Lyon, 2016) attended by the data service team coleaders.

The Queensland/Pittsburgh RDM service model has similarities with the tiered and differentiated reference service models introduced in the 1990s and their evolution into more complex collaborative triage models for the participatory culture of the 21st century, emphasising teamwork, communities of practice and professional learning among peers (Chauvet, Bourbous and Liston, 2016; LaMagna, Hartman-Caverly and Marchetti, 2016). However, a key feature of the model elaborated for research data services is the collaborative blending of functional/technical expertise with disciplinary understanding at the point of delivery, which represents a step towards minimising the specialist silo-based practices traditionally favoured by libraries. Figure 1 presents a composite synthesis of the two triangle models for research data services augmented to bring out key features. 


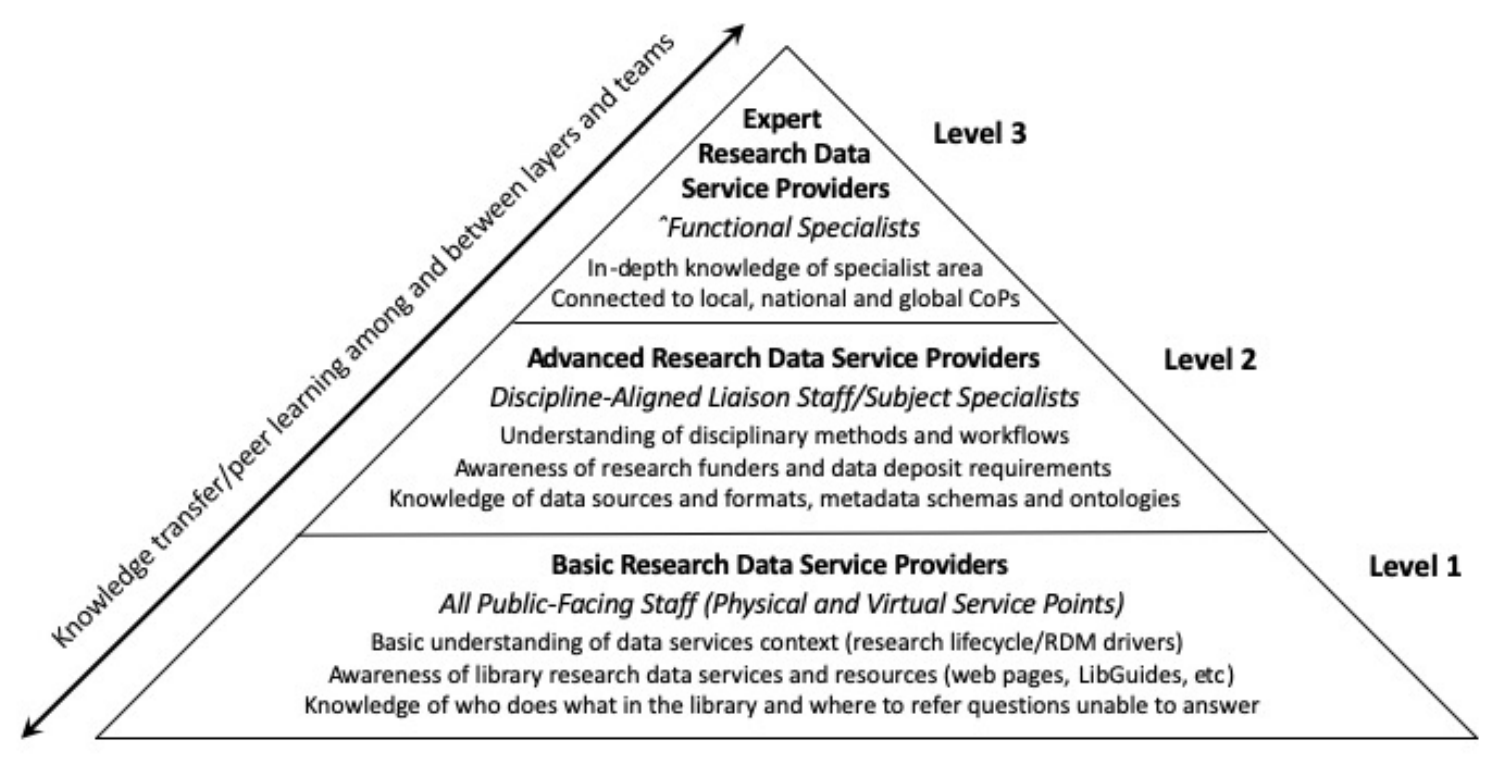

Figure 1. Participatory knowledge transfer and service delivery model for RDM support

Weiss $(2018,162,166)$ forecasts 'all librarians, regardless of their current stripe, inclination, or area of specialization, will need to be "assessment" and "big data" librarians as part of their core professional competencies' and 'Partnerships and collaborative efforts will become essential activities for librarians in the big data era'. Indeed, it is now fairly clear all library staff in all sectors will increasingly need at least basic data literacy/fluency to participate in the 21st century library, so all library managers need to consider options for workforce development. If we accept Kellam and Thompson's $(2016,1)$ definition of 'databrarianship' as 'a field that is characterized by a diversity of interests but united by our commitment to ensuring access to data, be they primary research data created by our institutions' researchers or secondary data used for analysis', we are all already 'databrarians', though our professional mission surely must go beyond access to cover other important issues surrounding data, including privacy and protection of personal data.

\section{Developments in education for librarians}

The literature on education in library and information science (LIS) reveals a culture of continuous improvement with educators striving to update and innovate their offerings to keep pace with developments in the field and demands of the profession; but they continually struggle to satisfy practitioners, who are frequent contributors to scholarship on the subject and quick to point out perceived gaps and problems in professional education. Scholars typically use a review, survey and/or case study as the basis for promoting additions or changes to content of courses and methods of delivery, and typically focus on a particular course or subject; many studies have examined the relevance, currency and fitness for purpose of 
established curricular content, including foundational subjects, while others have considered provision for emergent areas of practice. Some contributions have looked at educational provision more holistically at the programme level and beyond to include continuing professional development.

\section{Course development}

Research reveals significant variation, nationally and internationally, on education in information/knowledge organisation, and continuing debate on the balance between theory and practice, between traditional topics (cataloguing and classification) and contemporary concerns (metadata and linked data) and between technical know-how and 'soft skills' or 'behavioral competencies' (Alajmi and ur Rehman, 2016; Snow, 2019). Discussion around this core area of competence illustrates the questions surrounding nearly all areas of our professional curriculum. Snow (2019) advocates more emphasis on soft skills and social justice/ethical issues, noting that 21st century cataloguing/metadata librarians need to be collaborators and leaders, as well as creative, flexible, service-oriented problem solvers with initiative, ethical sensitivity and interpersonal communication skills, which is in line with core competencies agreed for cataloguing and metadata professionals (Frederick, 2018).

Management education is another continuing concern, raising similar issues about theory versus practice, emphasising social justice and ethics, and extending requirements from basic to advanced courses on topics such as advocacy and marketing (Pettitt, 2018; Singh and Vorbach, 2017). Singh and Vorbach (2017) report partnering with practitioners to develop a set of dualpurpose courses for students and mid-level professionals. Pettitt (2018) highlights extraordinary variations in the balance between required and elective courses in American programmes, where the required core can range from one-sixth (two courses) to half the curriculum, one-third being a common requirement - in contrast to the UK and other countries where required elements often account for two-thirds of the programme.

\section{Curriculum quality}

Inadequate preparation of librarians for their roles in learning and teaching has been a recurring theme in the literature for decades and now surpasses cataloguing education as the issue attracting the most criticism from practitioners, who highlight the 'contradiction' (DaviesHoffman et al, 2013, 9), 'troubling disconnect' (Brecher and Klipfel, 2014, 43) and 'severe mismatch' (Hensley, 2015, 315) between academic curricula and library practice at a time when 'instruction constitutes a core activity for most librarians' (Davies-Hoffman et al, 2013, 10) and 'almost all librarians teach in some manner throughout their career, whether it be for students and faculty as formal library instruction, at the reference desk, as part of outreach efforts, or staff training initiatives' (Hensley, 2015, 317). The role of librarians in facilitating self-directed and problem-based learning has long been recognised in the reference work of academic libraries (Currie, 2000; Miller 2001) and in lifelong learning support in public libraries (Nielsen and Borlund, 2014), where instructional work may cover 'accessing and using new technologies, 
finding and applying for jobs, and navigating information sources for research and personal needs' (Saunders, 2015, 2).

As Carlozzi $(2018,201,202)$ asserts teaching is 'Not an Elective Part of the Job'! It has been a central responsibility for decades and 'is both a traditional and a continually growing part of our profession. ...neither a historical burden nor a contemporary quirk'. Yet many librarians feel they lack the pedagogical competencies for such roles, especially in public libraries (Nielsen and Borlund, 2014). While a growing proportion of LIS programmes offer one or more specialist electives on the subject and some offer apprenticeships/field experiences, others cover the topic only as a minor part of a reference course and few schools make pedagogy a major part of their core curriculum; the quality of offerings has also been criticised (Brecher and Klipfel, 2014; Davies-Hoffman et al, 2013; Hensley, 2015; Raju, 2017; Saunders, 2015). Many instruction librarians organise their own pedagogical education after they graduate, while practitioners with less formal teaching roles learn on the job through trial and error, peer observation or mentoring. Professional development offerings generally focus on formal teaching and are often too brief to provide the scaffolded contextualised experiential learning needed to build the competence and confidence of teaching librarians.

\section{Programme renewal}

Several studies in the past five years have taken a more fundamental look at LIS education informed by practitioner and other stakeholder views on gaps in current provision and requirements for the future, including one-off contributions (Bedford, Donley and Lensenmayer, 2015; Pettitt, 2018) and multi-year projects (Abels, Howarth and Smith, 2018; Bertot, Sarin and Percell, 2015; Lankes, Stephens and Arjona, 2015). Collectively the studies offer a range of perspectives on professional education, using various lenses to frame their investigations, such as intellectual capital (Bedford et al, 2015), professional apprenticeships (Pettitt, 2018), participatory/convergence culture (Lankes et al, 2015) and design thinking (Abels et al, 2018). The reports vary in focus, but share several common themes reflecting both longstanding concerns and emerging interests.

\section{Social mission}

Studies emphasize a renewed social purpose for libraries, reinterpreting our historic commitment to social responsibility as a proactive role working for social justice. Thus Lankes et al $(2015,563)$ characterise the mission of librarians as 'to foster conversations that improve society through knowledge exchange and social action' [emphasis added], placing Transformative Social Engagement - which embraces activism, social responsibility, critical social analysis and understanding community needs - as their priority core skillset. Abels et al (2018) identify 'Understanding social issues and social change' as an important competency, while Bedford et al (2015) list social intelligence and social networks among new behavioural competencies for information professionals. Bertot et al $(2015,7-8)$ also foreground the social dimension in their vision of information professionals (and their organisations) as 'community change agents' and specifically 'critical leaders of social innovation in their communities' [emphasis added], interpreted to include 'areas such as health, education and learning, 
economic development, poverty and hunger, civic engagement, preservation and cultural heritage, and research innovation'.

\section{Asset management}

Three studies signal a shift in thinking that de-emphasizes holding physical collections and digital content to focus on organising materials for users and making them accessible (Lankes et al, 2015); facilitating content creation and curation by individuals, organisations and communities, and helping people leverage their data as digital assets for community problemsolving (Bertot et al, 2015); and extending library stewardship from information to knowledge resources, managing and leveraging intellectual assets, including human, structural and, particularly, relational capital as knowledge facilitators in their communities (Bedford et al, 2015). Bertot et al (2015) present this as a shift from collections to communities ('people, not stuff'), a user-centred approach that goes beyond users interacting with holdings in passive impersonal transactions to librarians proactively facilitating individual transformations through learning and skills development in interactive and immersive environments, such as coding workshops and makerspaces. Rather than building collections, librarians will enhance the understanding of primary data/information sources, and maintain and sustain local data infrastructures (hubs, repositories), supporting civic engagement, decision making and open government.

\section{Experiential learning}

Studies continually flag the need to strengthen experiential learning to develop the behavioural competencies/soft skills sought by employers and needed for community engagement and relationship building, providing technical help to users and fulfilling roles as knowledge/learning facilitators: Bedford et al $(2015,108)$ argue such competencies should be 'elevated to the same status as functional competencies'. Many programmes promote experiential options including course projects involving practical work-related assignments, service learning, field placements, individual research or dissertations and voluntary or paid employment/internships (Bird and Crumpton, 2018; Huggins, 2017). But practitioners complain few programmes make substantial field experience a core requirement and such experiences are poorly designed and insufficiently immersive compared with other disciplines; they advocate mandatory fieldwork as a culminating experience to support integration into the profession and transition to employment and having more experiential learning in foundational courses to integrate theory, practice and professional values from the outset (Goodsett, 2018; Pettitt, 2018).

Research indicates field experiences work best when accompanied by class discussion and critical reflection to help students internalise their professional role in the community (Caspe and Lopez, 2018). Using 'studio-like' classes (Lankes, 2011, 179), introducing 'studio-based teaching' (Abels et al, 2018, 80) or programmatically 'setting education in a studio environment' forming a continuous 'reflective practicum' (Clarke and Bell, 2018, 205, 206) could complement learning in the field and emulate the design methods being adopted in participatory library practice. 


\section{Responses to professional education challenges}

While openness, participation and datafication have been live issues in higher education for more than a decade, the professional education response has generally been slow and frequently inadequate, particularly in incorporating shifts in thinking and changes to practice evident in the field into the core curriculum. Recent re-envisioning projects have started to move things in the right direction, but there are questions around how far and how fast, with little evidence yet of the radical change many have flagged as necessary. However, some iSchools have taken bold steps to re-engineer their programmes in ways that offer pointers towards a new order, including the University of Pittsburgh, which adopted the concepts of new librarianship, digital literacy and human-centric design as the intellectual foundation for its redesigned curriculum launched in 2018.

\section{Developing new databrarians}

Curriculum development for data-related roles in libraries and archives began in the mid-2000s when federal grants kick-started experiments in the US with new specialised courses on data curation, e-science and digital humanities, often combined with revisions of existing courses to form specialist tracks through Master's degrees or additional certificates. Many initiatives featured significant hands-on and/or practice-based components, sometimes involving extended fieldwork, highlighting perceptions of data management as boundary-stretching technology-intensive work (Corrall, 2012). One problem with these pioneering efforts was their focus on developing information professionals for specialist roles in data management/curation and neglect of the equally important task of preparing practitioners to integrate data resources and practices into core library functions which resulted in variable progress with incorporating emergent library data concepts and practices (such as 'data curation profiles', 'data interviews' and 'institutional data collection') into mainstream courses on reference, instruction and collection development, slowing the adoption of data-oriented practices in libraries (Corrall, 2012).

Education for data curation, data science and data analytics continues to grow with more courses, concentrations, certificates, diplomas and degrees being offered by iSchools in the US and other countries, but many LIS programmes still lack any data-related courses (Kim, 2016; Ortiz-Repiso, Greenberg, and Calzada-Prado, 2018). Generalist/non-specialist data education has received little attention, although a few iSchool educators have developed RDM resources suitable for both students and practitioners. Sheffield faculty collaborated with librarians from three universities on a multi-purpose OER 'suitable for practitioners' self-directed CPD, for internal training by libraries to their staff, and for embedding into the postgraduate taught (PGT) curriculum' providing learning materials for liaison librarians and others supporting research - not data specialists - that can be reused face-to-face or online (Cox, Verbaan and Sen $(2014,16)$. Other educator-practitioner partnerships for RDM training include a MOOC developed by the University of North Carolina iSchool with the University of Edinburgh data library (Tibbo, 2016) and a free online course created by US research librarians offering optional continuing education credits from Simmons University (Library Connect, 2020). 
One stand-out UK initiative responding specifically to the need for generalist data education is the MLIS foundational course developed at City University London, 'Data, Information, Technologies and Applications' (also known as 'The Story of Data'). Designed as a major revision of a core technology course to reposition it as a socio-technical introduction to data handling, it aims to develop the data literacy/data fluency of new professionals and is predicated on the assumption that 'all library and information professionals, in all sectors, will need to gain at least a basic appreciation of the issues around data, both technical and socio-ethical' (Robinson and Bawden, 2017, 313, 316). The case study emphasises the importance of balancing the technical, practical and social/ethical elements of the course in a way that meets the needs of librarians as data practitioners as distinct from other professionals with data-related roles.

In the US, the University of Pittsburgh has also moved in this direction placing data front and centre of its redesigned MLIS programme (http://sci.pitt.edu/mlis-redesign/) implemented in 2019-20. The MLIS now has six required courses (instead of the previous four): a new foundational core of three courses and a new 'design methods sequence' (three courses). Box 1 shows the course descriptions for the first two core courses.

\section{LIS 2020 LIFECYCLES OF DATA AND INFORMATION}

Using lifecycles of data and information as a grounding device for exploring the stages of data/information creation, description, storage, processing, management, preservation, sharing and reuse. Different lifecycle conceptualizations and a range of broad types of data and information from contexts including government data, corporate data, research data, social media data, archival records and citizen/personal data.

http://courses.sci.pitt.edu/courses/view/LIS-2020

\section{LIS 2030 DATA AND INFORMATION IN SYSTEMS}

Introduction to the concepts and technologies around data, code, metadata, and databases. Basic data types and file formats, code to manipulate data, the generation of metadata about data, and modeling databases to persistently store and structure data.

http://courses.sci.pitt.edu/courses/view/LIS-2030

Box 1. The new foundational core of the University of Pittsburgh MLIS

Evidence from library practitioners working with data confirms the need for a data-oriented core curriculum, revealing mixed opinions on how well their education prepared them for dealing with data in the library workplace: a majority had not taken data curation courses, but reported their professional education provided 'a solid foundation to then learn on the job', with information organisation, metadata theory and digital preservation the most useful courses. Respondents highlighted competency gaps or shortcomings in research methods and data interpretation, suggesting master's courses should 'require all students, whether specializing in data curation or not, to conduct research that included handling and analyzing data' to provide experience of 'hands-on-learning with data' (Thomas and Urban, 2018, 417). 
The study concludes a dedicated specialisation is not necessary; programmes should instead focus on practical research skillsets including statistical analysis.

Thomas and Urban (2018) also suggest iSchools should 'adapt applied curricula from datadriven disciplines, for technical as well as relational training' for all, and build partnerships on campus 'to create "immersive," embedded practical education', referencing the approach pioneered at Pittsburgh by Liz Lyon (2016), which gave students mini service-learning experiences by embedding them in the workflows and cultures of research labs in different disciplines, as well as educating the partner researchers about good practices in data management and infrastructures. Lyon's (2016) classes included a mix of LIS master's and doctoral students as well as library practitioners working in liaison, metadata, repository management and digital scholarship, representing both specialist data-related roles and others where data-based activities may be a major or minor part of their job.

\section{Preparing engaged participants}

The participatory culture of the digital network world requires practitioners who are socially engaged, participating in the activities of their communities and delivering expertise/support embedded (physically or virtually) in the workflows and lifeflows of their users, which in turn requires both technical/functional and behavioural competencies - including expertise in learning facilitation and technology translation, user-centred design and assessment methods, and abilities in communication and interaction, collaboration and relationship management, creative thinking and self-reflection (Bedford et al, 2015; Fleming-May et al, 2018). Such attributes are not new: they have surfaced in skills debates over decades, though the language may have changed (Fisher, Hallam and Partridge, 2005; Partridge, Lee and Munro, 2010). However the Web 2.0 world of social networks, mobile devices, hacker/maker culture and multimedia storytelling has raised the stakes with change happening faster and skillsets deployed differently in new contexts; Librarian 2.0 is a new 'state of mind' that requires a 'different mindset or attitude' (rather than a different skillset) and a change in the way library and information professionals think about their profession and 'what it means to be an LIS professional' (Partridge et al, 2010, 315, 330-31).

Another study of future skill requirements with a wider range of information professionals produced similar results, and foregrounded the stand-out qualities for the future as a passion for their sector/domain/discipline, or 'a "whole of life" approach' to their profession, coupled with 'an understanding of why we do what we do' (Howard et al, 2016), confirming the professional identity of librarians, including the values and ethics of the profession (ways of being), as an essential dimension of library education alongside professional knowledge (ways of thinking or understanding) and professional practice (ways of doing or acting and contexts of application), as envisioned in the Carnegie Foundation's professional apprenticeship model (Pettitt, 2018).The key point here is that in contemporary social environments, where library professionals are expected to act as community change agents and lead social innovation, identity development needs to move beyond socialising students into their professional roles and require them to debate and critically reflect on their roles in the community and society. 
The third core course of the new Pittsburgh MLIS is designed to socialise new professionals into their roles in the community and society through a capstone/culminating experience in their final term. Box 2 displays the course description.

\section{LIS 2040 THE INFORMATION PROFESSIONAL IN THE COMMUNITY}

Provides the context as well as a forum for students to discuss, understand and critique value systems, ethical frameworks and power structures embedded in information technologies, policies, systems and institutions. Emphasizing the importance of design, evaluation and engagement with communities through institutions and technologies ranging from public library systems to start ups, the course foregrounds the role of information professionals as active community members as well as the impact of the information professions on society. http://courses.sci.pitt.edu/courses/view/LIS-2040

Box 2. The capstone component of the new foundational core at Pittsburgh

The participatory society demands education programmes that integrate an orientation to academia and theory with an orientation to organisations and practice and an orientation to society and community. Having acknowledged the key role of experiential learning in preparing librarians to become engaged participants in the network society, the question is what kinds of learning experiences to provide. The growth in libraries of makerspaces and similar facilities such as digital scholarship centres as sites for learning and research emphasises new dimensions to the educational role of librarians that need to be integrated into their development as knowledge facilitators. Einarsson and Hertzum (2019) identify various ways librarians can scaffold formal, non-formal and informal learning in makerspaces through skilldriven, topic-driven, project-driven, socially-driven, self-directed and community-based activities, illuminating different relationships with learners. They also raise questions about professional identities in makerspaces around relationships with teachers, noting that librarians can assume the role of primary educator, peer collaborator or technical resource, which practitioners need to consider when working in such spaces.

Teaching is the key professional competency needed here, but specifically 'how to effectively integrate and facilitate learning with technologies...' (Koh and Abbas, 2015, 124). Practitioners thus need a more nuanced understanding of how library work in user-driven, informal, unstructured and creative learning environments has shifted not just from providing library services and resources to teaching information and technology skills, but towards learning facilitation and mentoring, which may include librarians educating teachers as well as children and adults, and 'requires somewhat different skillsets from teaching in the formal school environment' (Koh and Abbas, 2015, 124). Teaching and learning need to be upfront and central to the core curriculum for future library and information professionals as a major part of foundational courses, and of other required courses and contextual electives, and students must have the chance to observe and practice teaching and learning facilitation in both 'safe' spaces and real-world settings. 
Bowler et al (2019b) describe a novel methodology used to enhance facilitation practices and techniques of makerspace practitioners in public libraries using the Simple Interactions framework to analyse and reflect on video-recorded interactions with young people and then design and test context-specific changes to their practices in an iterative improvement cycle, supported by mini-learning modules and a community of practice. Similar participatory cocreative approaches could be designed to help LIS students develop their facilitation skills and reflective capacity via service-learning in practice settings. The key point here is the need to improve the quantity and quality of experiential learning. Such experiences must be designed for learning, not just opportunities for job sampling: students need to spend longer in the field to gain experience in building meaningful relationships with practitioners and users; educators need to plan and manage field assignments in collaboration with stakeholders (employers and users), defining and agreeing learning goals, performance tasks, course activities, teacher/facilitator roles, and assessment evidence.

The redesigned MLIS at Pittsburgh meets this need by requiring all students to engage in a yearlong three-part immersive collaborative learning and research experience delivered through three courses worth one-quarter of the credits for their master's degree. Box 3 describes the new three-course sequence introduced as part of the core curriculum.

\section{LIS 202I, LIS 2022 \& LIS 2023}

IDENTIFYING INFORMATION NEEDS OF KNOWLEDGE ORGANIZATIONS, IMPLEMENTING AND INTEGRATING SOLUTIONS

Teams of students work with (and inside) partner organizations over three terms to:

- Identify the organization's information needs;

- Implement information solutions to meet these needs;

- Integrate the solutions into the organization.

Student teams gather information about the mission and culture of their partner by observing organizational behaviour and listening to organizational actors to understand the context of the information needs and challenges identified. Teams propose, develop and implement prototypes of solutions to the challenges. They next work closely with their partners to integrate their proposed solutions into the organization, creating documentation, developing tutorials and delivering training as needed. They then assess the sustainability of their solutions through observation, measurement and feedback.

The three courses expose students conceptually and experientially to the mindset, values and methods of human-centred design thinking (Heath, 2016). The extended sequence of learningby-doing in real-world situations enables students to develop collaborative, interpersonal, teamwork, partnership and other soft skills that are hard to develop in traditional classroom settings, including qualitative contextual inquiry skills (Fichter, 2006). 
The requirement to design, build, and evaluate the impact and sustainability of a system, process or other product also enables students to apply knowledge and skills gained from their core foundational courses on data and information lifecycles and systems (and from their elective courses) in the real world before graduation. The ability to educate and communicate is critical to integration and requires students to develop expertise in teaching, learning and instructional design.

Box 3. The Design Methods sequence in the new core curriculum at Pittsburgh

\section{Promoting open practices}

The open movement is not just about scholarly practices, but its history in libraries connects it with the emergent scholarly communication (SC) specialty in academic libraries and discussion around professional development for open agenda has concentrated on specialist SC roles (Bolick, Bonn and Cross, 2017; Finlay, Tsou and Sugimoto, 2015). Relevant competency frameworks developed by practitioners generally target SC librarians/specialists (Calarco et al, 2016; NASIG, 2017), although NASIG $(2017,1)$ notes 'scholarly communication impacts all librarians, and as such, specific duties are often diffused through an organization'. There is also a parallel discussion on in-house education for liaison librarians with a focus on OA (Brantley, Bruns and Duffin, 2017; Rodriguez, 2015; Sewell and Kingsley, 2017), which has generated useful learning resources, such as the University of Cambridge downloadable 'handy guides' and three-minute YouTube videos on topics such as OA basics, Creative Commons licences and mirror journals (https://osc.cam.ac.uk/outreach/supporting-researchers-21st-centuryprogramme).

Literature reveals practitioner consensus that competency requirements here centre on repository development, publishing support, copyright/licensing and impact assessment (bibliometrics/altmetrics); and criticism of educators for not developing specialist SC courses (Bolick et al, 2017; Finlay et al, 2015; Raju, 2019) and failing to update courses on copyright, which often omit key developments such as Creative Commons, alternative licensing and other OA issues (Kawooya, Ferullo and Lipinski, 2019). Pittsburgh is a notable exception having revised and expanded its course on 'Copyright and Fair Use in the Digital Age' to encompass 'Intellectual Property and "Open” Movements' (http://courses.sci.pitt.edu/courses/view/LIS2184). In addition, the course leader maintains a blog (https://kipcurriercopyright.blogspot.com) enabling students and others to track changes in legislation and breaking news on copyright and open matters as they happen.

In the absence of SC provision, Bolick et al $(2017,24)$ argue librarians 'should start leveraging open education in our own professionalization', while students should be 'making contributions part of active and participatory learning' (just as Cambridge University librarians created reusable learning resources as part of their research support training). They describe their collaborative initiative with community practitioners to produce an open textbook/resource for SC with practitioner-contributed case studies they envisage being continually refreshed to maintain currency. While there may be a case for iSchools to provide SC courses alongside 
other MLIS specialist electives, there is a more important need for open practices such as linked open data, OERs, open government data, OA journals, open research data and open source software to be better integrated across the curriculum in both core and elective courses, notably in relation to collection development/asset management, community engagement, knowledge organisation, reference work, information literacy, research methods and systems/technology, as well as in foundational courses on data, information and knowledge in society.

Practitioner Sarah Potvin $(2013,72)$ describes her preparation for specialist work by customising an OA/SC pathway through her MLIS, orienting coursework to her personal interests and 'locating resources through research and self-teaching'. Potvin $(2013,70)$ argues that programmes must produce 'graduates that are universally aware of SC and the OA movement, regardless of their specialty....by teaching MLIS students about OA's core principles and enabling them to navigate the complex economic, legal, and political framework for $\mathrm{OA}^{\prime}$ and 'incorporating these skills as cross-curricular learning objectives', but also stresses the need for 'overlapping efforts of MLIS programs, self-study, and formal continuing education within or outside of the library' to provide the necessary foundational knowledge and keep it up to date - a message that applies to library education generally, which cannot keep up with changes in the field without closer collaboration and stronger partnerships across different learning settings.

LIS educators should also promote openness by displaying a personal commitment to the movement through adopting and/or creating OERs in their courses. Open resources librarian Stacy Katz (2020) found only half of the American educators she surveyed used OERs as learning resources and only a quarter covered the topic in their teaching, thus missing the opportunity to model good practice, diversify educational resources, reduce student debt and promote a vital aspect of library work. She suggests various ways to give students practical experience of working with OERs, including cataloguing and creating OERs.

\section{Transforming the professional learning landscape}

Education for library and information work needs to change radically to build professional capacity for transforming libraries into open participatory data-centric organisations. Educators need to move beyond tinkering and quick fixes to more fundamental re-engineering of programme content, course delivery and professional engagement.

We need to accept that we live, work and play in an open data-centric environment. Ten years ago, library director Martin Lewis $(2010,145)$ argued that data 'represents an integral part of the global research knowledge base, and so managing it should be a natural extension of the university library's current role', but a decade later many MLIS programmes are still treating data work as an esoteric activity. Data must become central to the required core curriculum and integrated into courses covering core library functions instead of being treated as a minority interest. Open practices similarly should be mainstreamed and presented alongside traditional practices as state-of-the-art, emergent, developing or aspirational, depending on the 
maturity level of the particular domain. Open resources, community assets, institutional outputs and user-generated content should likewise be mainstreamed and integrated in a holistic reconceptualisation of library collections as asset development and access management.

The educational activities of all library workers need to be explicitly acknowledged as a core function with substantial coverage in the core curriculum and priority given to preparing practitioners to act as educational developers and learning facilitators enabling and empowering situated learning around emerging technologies, data practices and other literacies. Behavioural competencies are another weak area of library and information programmes that need to be strengthened to complement traditional professional and emergent technical knowledge and skills. Reflective practice is an essential meta-competency for librarians that helps practitioners monitor and develop other competencies as new professionals and lifelong learners; reflective methodologies, techniques and tools should be formally introduced at the start of professional education and their use assessed and evaluated continuously and at the end of degree programmes through a capstone assignment such as a developmental showcase e-portfolio project.

Experiential learning needs to become a large part of the core curriculum so students can develop competence and confidence in the practical application of professional and technical knowledge and skills introduced in the classroom, particularly relational, facilitation and datahandling skillsets. Programmes need to provide prolonged mandatory immersive learning in real-world settings, managed in collaboration with stakeholders (employers and users), rather than relying on elective field experiences or internships and learning on the job after graduation. Micro-immersions of a few hours could be inserted in core courses as starter experiences; the studio model used in other disciplines could also be used to bridge the transition from classroom to fieldwork. Courses mixing full-time and part-time students with non-credit learners enable richer peer-learning experiences and can help participants appreciate the value of diverse perspectives on a problem.

The pace of change in our field is not going to slacken so practitioners in the field will always need resources and venues to continue their professional learning as new theories and practices come on stream. We need to see pre-service and in-service education as a continuum and recognise the mutual benefits of multi-purpose courses and other learning experiences for student librarians, recent graduates and experienced practitioners to work and create knowledge together. While there are now many more options for self-directed learning via online communities, webinars, OERs, MOOCs and digital badges, as well as conferences, workshops, talks, projects and in-house training, professional educators can contribute by developing frameworks for professional learning that bring everything together as curated collections for both students and practitioners. We need to democratise professional education by inviting wider participation with flexible programming that encourages learners to choose modes of access that work for them, mixing face-to-face and online learning in combinations that suit them, as well as empowering people to pursue subjects that interest and motivate their learning. 


\section{References}

Abels, E. G., Howarth, L. C., and Smith, L. C. (2018) 'Transforming Library and Information Science Education by Design', In Percell, J., Sarin, L. C., Jaeger, P. T., and Bertot, J. C. (eds) Re-envisioning the MLS: Perspectives on the Future of Library and Information Science Education (Advances in librarianship, Volume 44A), Emerald, 71-89.

ACRL (2015) Framework for Information Literacy for Higher Education. http://www.ala.org/acrl/standards/ilframework

Alajmi, B., and ur Rehman, S. (2016) 'Knowledge Organization Trends in Library and Information Education: Assessment and Analysis', Education for Information 32(4), 411-20.

Archambault, É., Amyot, D., Caruso, J., Campbell, D., Deschamps, P., Nicol, A. Provencher, F., Rebout, L., and Roberge, G. (2014) Summary Report - Evolution of Open Access Policies and Availability, 1996-2013. Science-Metrix. http://sciencemetrix.com/sites/default/files/science-metrix/publications/d 4.5_sm_ec dgrtd oa policies proportion oa 1996-2013 v05p_0.pdf

ARL Task Force on Wikimedia and Linked Open Data (2019). ARL White Paper on Wikidata: Opportunities and Recommendations, ARL \& Wikimedia Foundation. https://www.arl.org/resources/arl-whitepaper-on-wikidata/

Atkinson, J. (ed) (2018) Collaboration and the Academic Library: Internal and External, Local and Regional, National and International, Chandos.

Awre, C. L., Stainthorp, P., and Stone, G. (2016) 'Supporting Open Access Processes through Library Collaboration', Collaborative Librarianship 8(2) , 99-110. https://digitalcommons.du.edu/collaborativelibrarianship/vol8/iss2/8

Ayre, L. B., and Craner, J. (2017) 'Open Data: What It Is and Why You Should Care', Public Library Quarterly 36 (2), 173-84.

Barnes, C. (2013) 'MOOCs: The Challenges for Academic Librarians', Australian Academic and Research Libraries 44(3), 163-75. https://doi.org/10.1080/00048623.2013.821048

Bedford, D. A., Donley, J. K., and Lensenmayer, N. (2015) 'The Role of Librarians in a Knowledge Society: Valuing Our Intellectual Capital Assets', In Woodsworth, A. and Penniman, W. D. (eds) Current Issues in Libraries, Information Science and Related Fields (Advances in Librarianship, Volume 39), Emerald, 81-113.

Bertot, J. C., Sarin, L. C., and Percell, J. (2015) Re-Envisioning the MLS: Findings, issues, and Considerations, University of Maryland, College of Information Studies. https://ischool.umd.edu/news/re-envisioning-mls-final-report-released

Bird, N. J., and Crumpton, M. A. (2018) Short-term Staff, Long-Term Benefits: Making the Most of Interns, Volunteers, Student Workers, and Temporary Staff in Libraries, Libraries Unlimited.

Bolick, J., Bonn, M., and Cross, W. M. (2017) 'Community-Led Teaching and Learning: Designing an Open Educational Resource for Scholarly Communication and Legal Issues', Against the Grain (September), 23-4. http://hdl.handle.net/1808/25041 
Bond, P. (2013) 'Massive Open Online Courses for Professional Development and Growth', In Smallwood, C., Harrod, K., and Gubnitskaia, V. (eds) Continuing Education for Librarians: Essays on Career Improvement Through Classes, Workshops, Conferences and More, 28-34, McFarland.

Bowler, L., Acker, A., and Chi, Y. (2019a) 'Perspectives on Youth Data Literacy at the Public Library: Teen Services Staff Speak Out', Strategic Library 64, 17-25. https://www.libraryspot.net/SL/SL 07.2019/SL Perspectives.pdf

Bowler, L., Akiva, T., Colvin, S., and McNamara, A. (2019b) 'Facilitation in Library Makerspaces: A Prototype for a Professional Development Model', Information Research 24(4), paper colis1937. http://InformationR.net/ir/24-4/colis/colis1937.html

Brantley, S., Bruns, T. A., and Duffin, K. I. (2017) 'Librarians in Transition: Scholarly Communication Support as a Developing Core Competency', Journal of Electronic Resources Librarianship 29(3), 137-50.

Brecher, D., and Klipfel, K. (2014) 'Education Training for Instruction Librarians: A Shared Perspective', Communications in Information Literacy 8(1), 43-49. https://doi.org/10.15760/comminfolit.2014.8.1.164

Brophy, P. (2008) 'Telling the Story: Qualitative Approaches to Measuring the Performance of Emerging Library Services', Performance Measurement and Metrics, 9(1), 7-17.

Brown, E. A., Danilova, E., Morgan, H., and Thomas, A. (2018) 'Evolution of Research Support Services at an Academic Library: Specialist Knowledge Linked by Core Infrastructure', New Review of Academic Librarianship 24(3-4), 339-50,

Brown, R. A., Wolski, M., and Richardson, J. (2015) 'Developing New Skills for Research Support Librarians', Australian Library Journal 64(3), 224-34. https://doi.org/10.1080/00049670.2015.1041215

Bruns, A. (2013) 'From Prosumption to Produsage', In Towse, R., and Handke, C. (eds) Handbook on the Digital Creative Economy, 67-78, Edward Elgar. https://pdfs.semanticscholar.org/05db/154e87113915d0d6475e42ba31c1dda31259.pdf

Calarco, P., Shearer, K., Schmidt, B., and Tate, D. (2016) Librarians' Competencies Profile for Scholarly Communication and Open Access, COAR Joint Task Force on Librarians' Competencies in Support of E-Research and Scholarly Communication. https://www.coarrepositories.org/files/Competencies-for-ScholComm-and-OA June-2016.pdf

Carlozzi, M. (2018) 'Teaching in Libraries: Not an Elective Part of the Job', In Percell, J., Sarin, L. C., Jaeger, P. T., and Bertot, J. C. (eds) Re-envisioning the MLS: Perspectives on the Future of Library and Information Science Education (Advances in librarianship, Volume 44B), Emerald, 201-13.

Carlson, J., Fosmire, M., Miller, C. C., and Nelson, M. S. (2011) 'Determining Data Information Literacy Needs: A Study of Students and Research Faculty', Portal: Libraries and the Academy 11(2), 629-57.

Casey, M., and Savastinuk, L. (2007). Library 2.0: A Guide to Participatory Library Service, Information Today.

Casey, M. E., and Savastinuk, L. C. (2006) 'Library 2.0: Service for the Next-Generation Library', Library Journal 131(1), 40-2. https://www.libraryjournal.com/ 
Caspe, M., and Lopez, M. E. (2018) 'Preparing the Next Generation of Librarians for Family and Community Engagement', Journal of Education for Library and Information Science 59(4), 157-78.

Chauvet, M., Bourbous, V., and Liston, F. (2016) 'Service Matters: Single Service Point as a Collaborative and Professional Learning Initiative for Service Excellence', Journal of Access Services 13(2), 80-90.

Clarke, R. I., and Bell, S. (2018) 'Transitioning from the MLS to the MLD: Integrating Design Thinking and Philosophy into Library and Information Science Education', In Percell, J., Sarin, L. C., Jaeger, P. T., and Bertot, J. C. (eds) Re-envisioning the MLS: Perspectives on the Future of Library and Information Science Education (Advances in librarianship, Volume 44A), Emerald, 195-214.

Collister, L. B., and Deliyannides, T. S. (2014) 'The Library as Publisher', The Serials Librarian 66, 20-29.

Connaway, L. S. (2017) 'Putting the Library in the Life of the User: Listen, then Lead, to Promote a Unique and Compelling Role for Academic Libraries', Choice 54(10), 1442-5.

Corrall, S. (2012) 'Roles and Responsibilities: Libraries, Librarians and Data', In Pryor, G. (ed) Managing Research Data, Facet, 105-33.

Corrall, S. (2015) 'The Open Movement: What Libraries Can Do', In Where Do We Go From Here? Proceedings of the Charleston Library Conference, 559-70. https://doi.org/10.5703/1288284316319

Cox, A., Verbaan, E., and Sen, B. (2014) 'A Spider, an Octopus, or an Animal Just Coming into Existence? Designing a Curriculum for Librarians to Support Research Data Management', Journal of eScience Librarianship 3(1), 115-30. https://doi.org/10.7191/jeslib.2014.1055

Cryer, E. (2011) 'Incorporating Open Access into Libraries', Serials Review 37(2), 103-107. Currie, C. L. (2001) 'Facilitating Adult Learning: The Role of the Academic Librarian', The Reference Librarian 33(69-70), 219-31.

Davies-Hoffman, K., Alvarez, B., Costello, M., and Emerson, D. (2013) 'Keeping Pace with Information Literacy Instruction for the Real World: When Will MLS Programs Wake up and Smell the LILACs?', Communications in Information Literacy 7(1), 9-23.

https://doi.org/10.15760/comminfolit.2013.7.1.131

Denlinger, K. (2016) 'Experimenting with Massive Open Online Courses for Library Outreach and Institutional Awareness of Library Expertise', In Rice, S., and Gregor, M. N. (eds) E-Learning and the Academic Library: Essays on Innovative Initiatives, 52-61, McFarland.

Díaz, J. O. (2014) 'The Roles of Engagement at the Ohio State University Libraries: Thoughts from an Early Adopter', The Reference Librarian 55(3), 224-33.

Einarsson, Á., and Hertzum, M. (2019) 'Scaffolding of Learning in Library Makerspaces', In FabLearn Europe '19, May 28-29, 2019, Oulu, Finland, ACM. http://mortenhertzum.dk/publ/FabLearnEU2019.pdf

Fichter, D. (2006) 'Using Contextual Inquiry to Build a Better Intranet', Online 30(5), 46-8.

Finlay, C., Tsou, A., and Sugimoto, C. (2015) 'Scholarly Communication as a Core Competency: Prevalence, Activities, and Concepts of Scholarly Communication Librarianship as Shown through Job Advertisements', Journal of Librarianship and Scholarly Communication 3(1), eP1236. https://doi.org/10.7710/2162-3309.1236 
Fisher, B., Hallam, G., and Partridge, H. (2005) 'Different Approaches: Common Conclusions: The Skills Debate of the Twenty-First Century', New Review of Academic Librarianship 11(1), 13-29.

Fleming-May, R., Mays, R., Walker, T., Forrester, A., Tenopir, C., Bilal, D., and Allard, S. (2018)

'Experience Assessment: Designing an Innovative Curriculum for Assessment and UX

Professionals', Performance Measurement and Metrics 19(1), 30-39.

Fontichiaro, K., and Oehrli, J. A. (2016) 'Why Data Literacy Matters', Knowledge Quest 44(5), 20 -

27. https://files.eric.ed.gov/fulltext/EJ1099487.pdf

Frederick, D. E. (2018) 'Core Competencies for Cataloging and Metadata Professional Librarians

- The Data Deluge Column', Library Hi Tech News 35(8), 15-20.

Fried Foster, N. (ed) (2014) Participatory Design in Academic Libraries: New Reports and

Findings, Council on Library and Information Resources.

https://www.clir.org/pubs/reports/pub161/

Goodsett, M. (2018) 'Exploring Culminating Experiences: Bridging the Gap between Theory and

Practice in LIS Education', In Percell, J., Sarin, L. C., Jaeger, P. T., and Bertot, J. C. (eds) Re-

envisioning the MLS: Perspectives on the Future of Library and Information Science

Education (Advances in librarianship, Volume 44A), Emerald, 91-108.

Hamilton, M., Kernohan, D., and Jacobs, N. (2017) Open by Default? How Can We Make the Most of Open Practices in Research, Education and Skills? Jisc.

https://www.jisc.ac.uk/reports/open-by-default

Heath, P.-J. (2016) 'Applying Human-Centred Design to the Library Experience', In Priestner, A., and Borg, M. (eds) User Experience in Libraries: Applying Ethnography and Human-Centred Design, Routledge, 49-67.

Henkel, M., Ilhan, A., Mainka, A., and Stock, W. (2018) 'Open Innovation in Libraries', In HICSS51: Proceedings of the 51st Hawaii International Conference on System Sciences, January 36, 2018, Waikoloa Village, HI, USA, 4151-60. http://hdl.handle.net/10125/50411

Hensley, M. K. (2015) 'Improving LIS Education in Teaching Librarians to Teach', In ACRL 2015: Creating Sustainable Community, March 25-28, Portland, OR, 315-22.

http://www.ala.org/acrl/acrl/conferences/acrl2015/papers

Hill, H., and Bossaller, J. (2013) 'Public Library Use of Free E-Resources', Journal of Librarianship and Information Science 45(2), 103-12.

Hopkins, P., Hare, J., Donaghey, J., and Abbott, W. (2015) 'Geo, Audio, Video, Photo: How Digital Convergence in Mobile Devices Facilitates Participatory Culture in Libraries', Australian Library Journal 64 (1), 11-22.

Horton, V. (2013) Going “All-in” for Deep Collaboration', Collaborative Librarianship 5(2), 65-9. https://digitalcommons.du.edu/collaborativelibrarianship/vol5/iss2/1/

Howard, K., Partridge, H., Hughes, H., and Oliver, G. (2016) 'Passion Trumps Pay: A Study of the Future Skills Requirements of Information Professionals in Galleries, Libraries, Archives and Museums in Australia', Information Research 21(2), paper 714. https://InformationR.net/ir/21-2/paper714.html

Howe , J. (2006). 'The Rise of Crowdsourcing', Wired 14(6). https://www.wired.com/2006/06/crowds/

Huggins, S. (2017) 'Practice-based Learning in LIS Education: An Overview of Current Trends', Library Trends 66(1), 13-22. 
Hvenegaard Rasmussen, C. (2016) 'The Participatory Public Library: The Nordic Experience', New Library World 117(9/10), 546-56.

Jacobson, T. E., and Mackey, T. P. (2013) 'Proposing a Metaliteracy Model to Redefine Information Literacy', Communications in Information Literacy 7(2), 84-91. https://doi.org/10.15760/comminfolit.2013.7.2.138

Jenkins, H., Clinton, K., Purushotma, R., Robison, A. J., and Weigel, M. (2006) Confronting the Challenges of Participatory Culture: Media Education for the 21st Century [White paper], MacArthur Foundation. https://www.macfound.org/media/article_pdfs/JENKINS WHITE_PAPER.PDF.

Katz, S. (2020) 'The Case for Open Educational Resources in Library and Information Science Education', Library Trends 69(2) (in press).

Kawooya, D., Ferullo, D., and Lipinski, T. (2019) 'Library and Information Science Curriculum in a Changing Professional Landscape: The Case of Copyright Education in the United States', Journal of Copyright in Education and Librarianship 3(2), 1-43. https://doi.org/10.17161/jcel.v3i2.6974

Kellam, L. M., and Thompson, K. (eds) (2016) Databrarianship: The Academic Data Librarian in Theory and Practice, Association of College and Research Libraries.

Kim, J. (2016) 'Who is Teaching Data: Meeting the Demand for Data Professionals', Journal of Education for Library and Information Science 57(2), 161-73.

Koh, K., and Abbas, J. (2015) 'Competencies for Information Professionals in Learning Labs and Makerspaces', Journal of Education for Library and Information Science 56(2), 114-29.

Kwanya, T., Stilwell, C., and Underwood, P. G. (2015) Library 3.0: Intelligent Libraries and Apomediation, Chandos.

LaMagna, M., Hartman-Caverly, S., and Marchetti, L. (2016) 'Redefining Roles and Responsibilities: Implementing a Triage Reference Model at a Single Service Point', Journal of Access Services 13(2), 53-65.

Lankes, R. D. (2011) The Atlas of New Librarianship, MIT Press. https://davidlankes.org/newlibrarianship/the-atlas-of-new-librarianship-online/

Lankes, R. D., Silverstein, J., and Nicholson, S. (2007) 'Participatory Networks: The Library as Conversation', Information Technology and Libraries 26(4), 17-33. https://doi.org/10.6017/ital.v26i4.3267

Lankes, R. D., Stephens, M., and Arjona, M. (2015) 'Participatory and Transformative Engagement in Libraries and Museums: Exploring and Expanding the Salzburg Curriculum', Journal of Education for Library and Information Science 56(S1), S61-S68

Lewis, D., Goetsch, L., Graves, D., and Roy, M. (2018) 'Funding Community Controlled Open Infrastructure for Scholarly Communication: The 2.5\% Commitment Initiative', College \& Research Libraries News 79(3), 133-6. https://doi.org/10.5860/crln.79.3.133

Lewis, M. (2010) 'Libraries and the Management of Research Data', in McKnight, S. (ed), Envisioning Future Academic Library Services: Initiatives, Ideas and Challenges, Facet, 14568.

Library Connect (2020) 'RDMLA: Free Training Course for Librarians Now Offers the Opportunity to earn CE Credits', Library Connect, 4 February. https://libraryconnect.elsevier.com/articles/free-rdm-training-librarians 
Lyon, L. (2016) 'Librarians in the Lab: Toward Radically Re-Engineering Data Curation Services at the Research Coalface', New Review of Academic Librarianship 22(4), 391-409.

Macy, K. V., and Coates, H. L. (2016) 'Data Information Literacy Instruction in Business and Public Health: Comparative Case Studies', IFLA Journal 42(4), 313-27. https://www.ifla.org/files/assets/hq/publications/ifla-journal/ifla-journal-42-4 2016.pdf

Mann, L. (2018) 'Making a Place for Makerspaces in Information Literacy', Reference \& User Services Quarterly 58(2), 82-6. https://doi.org/10.5860/rusq.58.2.6927

Martin, S., and Oehrli, J. A. (2016) 'Diving into Data: Developing Data Fluency for Librarians' In Ragains, P., and Wood, M. S. (eds) The New Information Literacy Instruction: Best Practices, Rowman \& Littlefield, 153-72.

Mattern, E., Brenner, A., and Lyon, L. (2016) 'Learning by Teaching about RDM: An Active Learning Model for Internal Library Education', International Journal of Digital Curation 11(2), 27-38. https://doi.org/10.2218/ijdc.v11i2.414

Maybee, C., and Zilinski, L. (2015) 'Data Informed Learning: A Next Phase Data Literacy Framework for Higher Education', Proceedings of the Association for Information Science and Technology 52. https://doi.org/10.1002/pra2.2015.1450520100108

Miller, J. M. (2001) 'A Framework for the Multiple Roles of Librarians in Problem-Based Learning', Medical Reference Services Quarterly 20(3), 23-30.

Murphy, H., and Tilley, E. (2019) 'Libraries Supporting Transition: Developing a Pre-Arrival Open Educational Resource (OER) for Taught Master's Students', New Review of Academic Librarianship 25(2-4), 271-94.

NASIG (2017) Core Competencies for Scholarly Communication Librarians. https://nasig.org/Competencies-Scholarly-Communication

Neal, J. G. (2011) 'Advancing from Kumbaya to Radical Collaboration: Redefining the Future Research Library', Journal of Library Administration 51(1), 66-76.

Nguyen, L. C. (2015) 'Establishing a Participatory Library Model: A Grounded Theory Study', Journal of Academic Librarianship 41(4), 475-87.

Nichols, J., Melo, M., and Dewland, J. (2017) 'Unifying Space and Service for Makers, Entrepreneurs, and Digital Scholars', portal: Libraries and the Academy 17(2), 363-74.

Nielsen, B. G., and Borlund, P. (2014) 'Public Libraries and Lifelong Learning', Perspectives of Innovations, Economics and Business 14(2), 94-102. https://doi.org/10.15208/pieb.2014.11

Ortiz-Repiso, V., Greenberg, J., and Calzada-Prado, J. (2018) ‘A Cross-Institutional Analysis of Data-related Curricula in Information Science Programmes: A Focused Look at the iSchools', Journal of Information Science 44(6), 768-84.

Otto, J. J., and Mullen, L. B. (2019) 'The Rutgers Open Access Policy Goes into Effect', Library Management 40(1/2), 59-73.

Partridge, H., Lee, J., and Munro, C. (2010) 'Becoming “Librarian 2.0”: The Skills, Knowledge, and Attributes Required by Library and Information Science Professionals in a Web 2.0 World (and Beyond)', Library Trends 59(1-2), 315-35.

Pawlowski, D. (2017) 'MOOCs: Power Tools for Public Librarians', In Alman, S. W., and Jumba, J. (eds) MOOCs Now: Everything You Need to Know to Design, Set Up, and Run a Massive Open Online Course, 13-18, Libraries Unlimited. 
Petrides, L., Goger, L., \& Jimes, C. (2016) 'The Role of “Open” in Strategic Library Planning', Education Policy Analysis Archives/Archivos Analíticos de Políticas Educativas 24 (36), 1-13. https://doi.org/10.14507/epaa.24.2478

Pettitt, K. (2018) 'Educating Librarians: Applying the Carnegie Foundation for the Advancement of Teaching Apprenticeship Model to the Education of Librarians', In Percell, J., Sarin, L. C., Jaeger, P. T., and Bertot, J. C. (eds) Re-envisioning the MLS: Perspectives on the Future of Library and Information Science Education (Advances in librarianship, Volume 44B), Emerald, 123-51.

Potvin, S. (2013) 'The Principle and the Pragmatist: On Conflict and Coalescence for Librarian Engagement with Open Access Initiatives', Journal of academic librarianship 39(1), 67-75.

Priestner, A., and Borg, M. (eds) (2016) User Experience in Libraries: Applying Ethnography and Human-Centred Design, Routledge.

Raju, J. (2017) 'To Teach or Not to Teach? The Question of the Academic Librarian's Pedagogical Competencies in the Digital Age', South African Journal of Higher Education 31(2), 251-69. https://doi.org/10.20853/31-2-1096

Raju, J. (2019) 'Embracing New Trends in Scholarly Communication: From Competency Requirements in the Workplace to LIS Curriculum Presence', Journal of Librarianship and Scholarly Communication 7(General Issue), eP2291. https://doi.org/10.7710/21623309.2291

Reed, J. B., and Jahre, B. (2019) 'Reviewing the Current State of Library Support for Open Educational Resources', Collection Management 44 (2-4), 32-43.

Robinson, L.., and Bawden, D. (2017) "'The story of data": A Socio-Technical Approach to Education for the Data Librarian Role in the CityLIS Library School at City, University of London', Library Management 38(6/7), 312-22.

Robinson, P., and Mather, L. W. (2017) 'Open Data Community Maturity: Libraries as Civic Infomediaries', URISA Journal: Journal of the Urban and Regional Information Systems Association 28, 31-8.

https://www.urisa.org/clientuploads/directory/Documents/Journal/Vol28 final.pdf

Rodriguez, J. E. (2015) 'Scholarly Communications Competencies: Open Access Training for Librarians', New Library World 116(7/8), 397-405.

Saunders, L. (2015) 'Education for Instruction: A Review of LIS Instruction Syllabi', The Reference Librarian 56(1), 1-21.

Schlak, T. (2018). Academic libraries and engagement: A critical contextualization of the library discourse on engagement. The Journal of Academic Librarianship, 44(1), 133-139.

Schmidt, B., Bertino, A., Beucke, D., Brinken, H., Jahn, N., Matthias, L., Mimkes, J., Müller, K., Orth, A. and Bargheer, M. (2018) 'Open Science Support as a Portfolio of Services and Projects: From Awareness to Engagement', Publications 6 (2), article 27. https://doi.org/10.3390/publications6020027

Sewell, C., and Kingsley, D. (2017) 'Developing the 21st Century Academic Librarian: The Research Support Ambassadors Programme', New Review of Academic Librarianship 23(23), 148-58.

Shanley, C., and De Voe, K. M. (2018) "'Survey Says . . ": Developing Students' Critical Data Literacy', In Agosto, D. E. (ed) Information Literacy and Libraries in the Age of Fake News, Libraries Unlimited, 151-66. 
Shumaker, D. (2012) The Embedded Librarian: Innovative Strategies for Taking Knowledge Where It's Needed, Information Today.

Singh, R., and Vorbach, J. (2017) 'Re-envisioning Management Education and Training for Information Professionals', Journal of Education for Library and Information Science 58(2), 94-105.

Snow, K. (2019) 'Shifting Sands and the Prophet's Dream: Exploring the Future of Information Organization Education', Journal of Education for Library \& Information Science 60(2), 13951.

Stephens, M. (2007). 'Web 2.0, Library 2.0, and the Hyperlinked Library', Serials Review 33(4), 253-6.

Thomas, C., and Urban, R. (2018) 'What Do Data Librarians Think of the MLIS? Professionals' Perceptions of Knowledge Transfer, Trends, and Challenges', College \& Research Libraries 79(3), 401-23. https://doi.org/10.5860/crl.79.3.401

Tibbo, H. (2016) 'New MOOC! Research Data Management and Sharing', EDINA Blogs, 24 February. http://blogs.edina.ac.uk/2016/02/24/new-mooc-research-data-managementand-sharing/

Turner, C. N., and Billings, M. S. (2019) 'Flipping an Academic Library Collection: A Path to a Global Open Scholarly Commons', Collection Management 44 (2-4), no. 2-4, 195-205.

Ullah, I., Khusro, S., Ullah, A., and Naeem, M. (2018) 'An Overview of the Current State of Linked and Open Data in Cataloging', Information Technology and Libraries 37(4), 47-80. https://doi.org/10.6017/ital.v37i4.10432

Wang, F., Wang, W., Wilson, S., and Ahmed, N. (2016) 'The State of Library Makerspaces', International Journal of Librarianship 1 (1), 2-16. https://doi.org/10.23974/ijol.2016.vol1.1.12

Weiss, A. (2018) Big Data Shocks: An Introduction to Big Data for Librarians and information Professionals, Rowman \& Littlefield

Yang, L., and Henry, C. L. (2015). 'How ARL Academic Libraries Present Open Web Resources - a Proposed Solution to Address Discoverability', Journal of Academic Librarianship, 41(5), 62935.

Zhan, M., and Widén, G. (2018) 'Public Libraries: Roles in Big Data', The Electronic Library 36(1), 133-45. 